\title{
KAJIAN CAPAIAN INDIKATOR KAPITASI BERBASIS PEMENUHAN KOMITMEN PELAYANAN (KBK) BPJS DI FKTP KOTA JAMBI
}

\author{
Armaidi Darmawan ${ }^{1}$, Erny K ${ }^{1}$, Rina Nofri $E^{1}$, Susantara W' ${ }^{1}$, Eka Realita ${ }^{2}$ \\ ${ }^{1}$ Departemen Kesehatan Masyarakat Fakultas Kedokteran dan Ilmu Kesehatan Universitas Jambi \\ ${ }^{2}$ Mahasiswa Prodi Kedokteran Fakultas Kedokteran dan IImu Kesehatan Universitas Jambi \\ E-mail: armaididarmawan@yahoo.co.id
}

\begin{abstract}
Background: The implementation of capitation payments based on fulfilling service commitments (KBK) is assessed by achieved indicators including contact rate, RRNS and RPPB. Based on data monev Jambi 2019 showed that indicators of KBK BPJS in province Jambi are not reached the target. This research to analyze the factors that affect the achievement of the targets of the BPJS indicators in the Contact rate, RRNS and RPPB in the FKTP in the city of Jambi in 2019.
\end{abstract}

Method: This study used a quantitative descriptive. This study done in 34 primary health care in Jambi city. The questionnaire filled by head of primary health care and p-care staffs as a respondent.

Result: The result in this study showed the dominant trouble in reaching the indicator contact rate was exorbitant of target was too high 29 (42.6\%). The problem of RRNS indicator was increasing the demand of hospital referral which 48 (70,6\%) samples answered. RPPB target was too high 35 (51.5\%).

Conclusion: The implementation of Capitation Based on Service Commitment in primary health care in Jambi City had not been done maximally.

Keywords : KBK, FKTP, BPJS

\footnotetext{
ABSTRAK

Latar Belakang : Pelaksanaan pembayaran kapitasi berbasis pemenuhan komitmen pelayanan (KBK) dinilai berdasarkan pencapaian indikator meliputi Angka Kontak, Rasio Rujukan Rawat Jalan Non Spesialistik (RRNS) dan Rasio Peserta Prolanis Rutin Berkunjung (RPPB). Berdasarkan data yang dilakukan oleh team Monev Provinsi Jambi 2019 indikator KBK BPJS di provinsi Jambi masih belum memenuhi target yang telah ditetapkan. Penelitian ini bertujuan menganalisis faktor-faktor yang mempengaruhi belum tercapainya target pemenuhan indikator KBK BPJS pada Angka Kontak, RRNS dan RPPB pada FKTP dikota Jambi tahun 2019.
} 
Metode : Penelitian ini menggunakan metode deskriptif kuantitatif. Penelitian ini dilakukan di 34 Fasilitas Kesehatan Tingkat Pertama (FKTP) kota Jambi. Instrumen penelitian ini menggunakan wawancara dengan panduan kuesioner kepada kepala FKTP serta petugas p-care diFKTP sebagai responden.

Hasil : Hasil penelitian menunjukkan bahwa kesulitan yang paling dominan dalam memenuhi target indikator Angka Kontak adalah terlalu tingginya target yang ditetapkan 29 (42.6\%), kesulitan dalam RRNS adalah meningkatnya permintaan rujukan 48 (70.6\%), dan kesulitan RPPB adalah terlalu tinggi target yang ditetapkan 35 (51.5\%).

Kesimpulan : pelaksanaan sistem Kapitasi Berbasis Komitmen Pelayanan di FKTP kota Jambi belum terlaksana secara maksimal. Masih ada faktor yang menyebabkan belum tercapainya indikator KBK sehingga membuat FKTP berada di zona tidak aman.

Kata kunci : KBK, FKTP, BPJS

\section{PENDAHULUAN}

Indonesia, pada tanggal 1 Januari 2014 telah didirikan suatu Badan Penyelenggara Jaminan Sosial Kesehatan yang selaras dengan tujuan Organisasi Kesehatan Dunia dalam mengembangkan jaminan kesehatan untuk semua penduduk. BPJS Kesehatan sebagai Badan Pelaksana merupakan badan hukum publik yang dibentuk untuk menyelenggarakan program jaminan kesehatan bagi seluruh rakyat Indonesia. Masyarakat membutuhkan jaminan kesehatan, tujuan diberlakukannya program Jaminan Kesehatan Nasional ini adalah untuk memenuhi kebutuhan kesehatan masyarakat yang layak yang diberikan kepada setiap orang yang telah membayar iuran atau iurannya dibayar oleh Pemerintah. Iuran Jaminan Kesehatan adalah sejumlah uang yang dibayarkan secara teratur oleh Peserta, Pemberi Kerja, dan/atau Pemerintah untuk program Jaminan Kesehatan. ${ }^{1,3,4,5}$

Berdasarkan BPJS Kesehatan, dapat disimpulkan bahwa program JKN menitikberatkan pada prinsip managed care, dimana terdapat empat pilar, yaitu promotif, preventif, kuratif, dan rehabilitatif. Prinsip ini difokuskan di Fasilitas Kesehatan Tingkat Pertama, seperti puskesmas, klinik, dan praktek dokter yang menjadi gerbang utama peserta BPJS Kesehatan dalam mengakses pelayanan kesehatan. Untuk itu, kualitas FKTP harus ditingkatkan agar masyarakat mendapatkan pelayanan kesehatan yang baik. Salah satu masalah kritis dalam pelayaan kesehatan adalah tersedianya fasilitas dan tenaga kesehatan yang merata di seluruh wilayah dengan kualitas yang terjaga. ${ }^{6,7,8}$

Berbagai jenis pengukuran, standar dan upaya untuk meningkatkan mutu pelayanan telah tersedia dan terus berkembang. Salah satunya adalah dengan metode pembayaran berbasis komitmen pelayanan. Saat ini telah diterapkan pembayaran Kapitasi Berbasis Pemenuhan Komitmen Pelayanan (KBK) yang telah dilaksanakan sejak tahun 2016. KBK 
merupakan bagian dari pengembangan sistem mutu pelayanan yang bertujuan untuk meningkatkan efisiensi dan efektifitas pelayanan kesehatan di Fasilitas Kesehatan Tingkat Pertama. $^{9}$

Kapitasi Berbasis Pemenuhan Komitmen Pelayanan adalah penyesuaian besaran tarif kapitasi berdasarkan hasil penilaian pencapaian indikator pelayanan kesehatan perseorangan yang disepakati berupa komitmen pelayanan Fasilitas Kesehatan Tingkat Pertama dalam rangka peningkatan mutu pelayanan. Pelaksanaan pembayaran kapitasi berbasis pemenuhan komitmen pelayanan dinilai berdasarkan pencapaian indikator yang meliputi: ${ }^{9}$

\section{a. Angka Kontak \\ b. Rasio Rujukan Rawat Jalan Non Spesialistik (RRNS) \\ C. Rasio Peserta Prolanis Rutin Berkunjung (RPPB) \\ d. Kegiatan kunjungan rumah khusus bagi Puskesmas \\ Dalam pelaksanaan pembayaran} KBK, penilaian terhadap FKTP dilihat berdasarkan pencapaian indikator yang meliputi; Angka Kontak $\geq 150$ per mil, Rasio Rujukan Rawat Jalan Non Spesialistik (RRNS) $<5 \%$, dan Rasio Peserta ProlanisRutin Berkunjung (RPPB) $\geq 50 \%$. Apabila FKTP dapat memenuhi indikator tersebut, maka FKTP termasuk di dalam zona aman. Khusus bagi puskesmas, terdapat indikator tambahan untuk mengetahui peneyelenggaraan kegiatan promotif preventif di puskesmas, yaitu Rasio Kunjungan Rumah yang harus mencapai $8,33 \%$ per bulan atau $100 \%$ per tahun. ${ }^{9}$

Berdasarkan data yang dilakukan oleh team Monitoring dan Evaluasi (Monev)
KBK Provinsi Jambi pada Januari 2017Maret 2019 indikator KBK BPJS di provinsi Jambi masih belum memenuhi target yang telah ditetapkan. Di Kota Jambi pada Januari 2017- April 2019 indikator KBK BPJS seperti Angka Kontak belum mencapai taget pemenuhan yaitu masih dibawah 150\% permil. Rasio Rujukan Rawat Jalan Non Spesialistik (RRNS) pada tahun 2018 dapat memenuhi target yaitu $<5 \%$, tetapi pada bulan Maret 2019 Rasio Rujukan Rawat Jalan Non Spesialistik (RRNS) melebihi target yang harusnya $<5 \%$. Rasio Peserta Prolanis Rutin Berkunjung (RPPB) belum dapat mencapai target pemenuhan yaitu masih dibawah 50\%. Sedangkan Rasio Kunjungan Rumah belum ada data dari BPJS Provinsi Jambi sehingga tidak dimasukan dalam penelitian ini. ${ }^{10}$

Untuk itu berdasarkan latar belakang tersebut peneliti berkeinginan meneliti "Kajian Pelaksanaan KBK BPJS pada FKTP diKota Jambi tahun 2019" untuk melihat faktor apa saja yang mempengaruhi belum tercapainya target pemenuhan indikator KBK BPJS pada Angka Kontak, Rasio Rujukan Rawat Jalan Non Spesialistik (RRNS) dan Rasio Peserta Prolanis Rutin Berkunjung (RPPB).

\section{METODE}

Jenis penelitian pada penelitian ini adalah deskriptif kuantitatif. Penelitian ini dilakukan dengan wawancara menggunakan panduan kuesioner dimaksudkan untuk mengumpulkan informasi mengenai kesulitan dalam menjalankan indikator KBK BPJS diFKTPnya. Dalam hal ini, metode penelitian deskriptif digunakan untuk mengetahui kajian 
pelaksanaan KBK BPJS pada FKTP diKota Jambi tahun 2019.

Populasi dalam penelitian ini adalah 55 FKTP (puskesmas, klinik pratama dan praktek dokter) yang bekerjasama dengan BPJS Kesehatan Kota Jambi. Teknik pengambilan sampel menggunakan nonprobability sampling dengan pengambilan secara consecutive sampling, dimana yang menjadi sampel penelitian adalah FKTP yang memenuhi kriteria inkulsi dan eksklusi yang dimasukan menjadi sampel penelitian. didapatkan jumlah sampel yang dibutuhkan dalam penelitian ini sebanyak 34 FKTP dengan masing masing responden setiap FKTP 2 responden yaitu kepala Puskesmas/kepala klinik/dokter praktek perorangan dan pertugas $p$-care.

Instrumen yang digunakan adalah wawancara dengan panduan kuesioner. kuesioner digunakan dengan pertanyaanpertanyaan terstruktur dalam bahasa Indonesia untuk mengambil data mengenai pencapaian indikator KBK BPJS kota Jambi tahun 2019. Dalam menggunakan kuisioner, peneliti mengajukan beberapa pertanyaan kepada responden dan setiap jawaban telah ditentukan dengan hasil ukur pada tabel definisi operasional.

\section{HASIL DAN PEMBAHASAN}

Penelitian ini dilakukan pada bulan Juli sampai bulan Agustus 2019 di 34 Fasilitas Kesehatan Tingkat Pertama (FKTP) kota Jambi yaitu 20 puskesmas, 10 klinik pratama, dan 4 dokter praktek perorangan. Pengambilan sampel pada penelitian ini dengan menggunakan wawanacara dengan panduan pengisian kuesioner kepada kepala FKTP (kepala puskesmas, kepala klinik dan dokter praktek perorangan serta petugas $p$ care di FKTP. Dengan masing masing 2 responden disetiap FKTP.

Tabel 1. Jumlah sampel kajian pelaksanaan KBK BPJS pada FKTP di kota Jambi tahun 2019

\begin{tabular}{llcc}
\hline No & \multicolumn{1}{c}{ FKTP } & Jumlah FKTP & Jumlah Responden \\
\hline 1 & Puskesmas & 20 & 40 \\
2 & Klinik Pratama & 10 & 20 \\
3 & Dokter Praktek Perorangan & 4 & 8 \\
\hline \multicolumn{2}{l}{ Jumlah } & 34 & 68 \\
\hline
\end{tabular}




\section{A. Gambaran Angka Kontak Kajian Pelaksanaan KBK BPJS Pada FKTP Di Kota Jambi Tahun 2019}

Tabel 2. Gambaran bentuk kontak yang menjadi catatan penilaian angka kontak di FKTP kota Jambi

\begin{tabular}{llccc}
\hline \multirow{2}{*}{ No } & \multirow{2}{*}{ Tempat Kontak } & $\mathrm{n}$ & \multicolumn{2}{c}{ Terjadi Kontak } \\
\cline { 4 - 5 } & & & Ya(\%) & Tidak(\%) \\
\hline 1 & FKTP & 68 & $68(100 \%)$ & 0 \\
2 & Puskesmas pembantu & 40 & $38(95 \%)$ & $2(5 \%)$ \\
3 & Puskesmas keliling & 40 & $36(90 \%)$ & $4(10 \%)$ \\
4 & Posyandu & 40 & $40(100 \%)$ & 0 \\
5 & Pos Pembinaan Terpadu (posbindu) & 40 & $40(100 \%)$ & 0 \\
6 & Pos Kesehatan Desa (poskesdes) & 40 & 0 & $40(100 \%)$ \\
7 & Posyandu lansia & 40 & $40(100 \%)$ & 0 \\
8 & Kunjungan rumah & 68 & $62(91.2 \%)$ & $6(8.8 \%)$ \\
9 & Sekolah & 40 & $38(95 \%)$ & $2(5 \%)$ \\
\hline
\end{tabular}

Berdasarkan tabel 2 didapatkan bahwa terjadi kontak di FKTP dari 68 reponden $68(100 \%)$ terjadi kontak dan yang tidak terjadi kontak 0 , dari 68 reponden terjadi kontak di kunjungan rumah 62 $(91.2 \%)$ yang tidak terjadi kontak $6(8.8 \%)$, dari 40 reponden terjadi kontak di posyandu 40(100\%) yang tidak terjadi kontak 0, dari 40 reponden terjadi kontak di posbindu $40(100 \%)$ yang tidak terjadi kontak 0 , dari 40 reponden terjadi kontak di posyandu lansia $40(100 \%)$ yang tidak terjadi kontak 0 , dari 40 responden terjadi kontak puskesmas pembantu $38(95 \%)$ yang tidak terjadi kontak $2(5 \%)$, dari 40 responden terjadi kontak di sekolah 38(95\%) dan yang tidak terjadi kontak $2(5 \%)$, dari 40 responden terjadi kontak dipuskesmas keliling 36(90\%) yang tidak terjadi kontak berjumlah $4(10 \%)$, dari 40 responden terjadi kontak di poskesdes 0 yang tidak terjadi kontak 40 (100\%).

Tabel 3. Gambaran terjadi kontak pada jenis pelayanan di FKTP kota jambi

\begin{tabular}{clccc}
\hline \multirow{2}{*}{ No } & \multirow{2}{*}{ Jenis Pelayanan } & $\mathrm{n}$ & \multicolumn{2}{c}{ Terjadi kontak } \\
\cline { 4 - 5 } & & & Ya (\%) & Tidak (\%) \\
\hline 1 & Kunjungan sakit & 68 & $68(100 \%)$ & 0 \\
2 & Kunjungan sehat & 68 & $52(76.5 \%)$ & $16(23.5 \%)$ \\
3 & Kunjungan sakit dan sehat & 68 & $40(58.8 \%)$ & $28(41.2 \%)$ \\
\cline { 4 - 4 } n : Jumlah responden & & &
\end{tabular}

Berdasarkan tabel 3 didapatkan bahwa dari 68 responden terjadi kontak pada jenis pelayanan kunjungan sakit 60(100\%) yang tidak terjadi kontak 0 , dari 68 responden terjadi kontak kunjungan sehat
$52(76.5 \%)$ yang tidak terjadi kontak $16(23.5 \%)$, dari 68 responden terjadi kontak kunjungan sakit dan sehat 40(58.8\%) yang tidak terjadi kontak 28(41.2\%). kunjungan sakit dan sehat $40(58.8 \%)$ tidak dicatat sebagai kunjungan 28(41.2\%). 
Tabel 4. Gambaran kesulitan dalam memenuhi target Angka Kontak di FKTP kota Jambi tahun 2019

\begin{tabular}{llcc}
\hline \multirow{2}{*}{ No } & \multirow{2}{*}{ Kesulitan Memenuhi Target Angka Kontak } & \multicolumn{2}{c}{ Kesulitan } \\
\cline { 3 - 4 } & & $\mathrm{Ya}(\%)$ & Tidak(\%) \\
\hline 1 & Terlalu tingginya target ( $\geq 150$ permil) & $29(42.6 \%)$ & $39(57.4 \%)$ \\
2 & Terbatasnya tenaga dokter dan paramedis & $9(13.2 \%)$ & $59(86.8 \%)$ \\
3 & Kurangnya dana operasional & $6(8.8 \%)$ & $62(91.2 \%)$ \\
4 & Tidak optimalnya petugas P-care & $21(30.9 \%)$ & $47(69.1 \%)$ \\
5 & Pasien berpindah tempat tinggal & $25(36.8 \%)$ & $43(63.2 \%)$ \\
\hline
\end{tabular}

Berdasarkan tabel 4 kesulitan dalam memenuhi target Angka Kontak terlalu tingginya target ( $\geq 150$ permil) $29(42.6 \%)$ yang tidak merasa kesulitan 39(57.4\%), pasien berpindah tempat tinggal $25(36.8 \%)$ yang tidak merasa kesulitan 43(63.2\%), tidak optimalnya petugas P-care 21(30.9\%) yang tidak merasa kesulitan 47(69.1\%), terbatasnya tenaga dokter dan paramedic 9(13.2\%) yang tidak merasa kesulitan $59(86.8 \%)$, kurangnya dana operasional $6(8.8 \%)$ yang tidak merasa kesulitan $62(91.2 \%)$.

Tabel 5. Kesulitan lainnya dalam memenuhi target indikator Angka Kontak ( $\geq 150$ permil)

\begin{tabular}{|c|c|c|}
\hline No & Jenis Kesulitan Lainnya & Frekuensi \\
\hline 1 & BPJS hanya menghitung 1 kali kunjungan dalam setiap bulan & $19(27,9 \%)$ \\
\hline 2 & $\begin{array}{l}\text { Gangguan internet, aplikasi p-care lemot menyulitkan dalam } \\
\text { menginput data di p-care }\end{array}$ & $15(22.1 \%)$ \\
\hline 3 & $\begin{array}{l}\text { Terlalu ribet pengisisn p-care yang harus mengukur lingkar perut } \\
\text { dan IMT yang menyulitkan }\end{array}$ & $13(19.1 \%)$ \\
\hline 4 & $\begin{array}{l}\text { Kurangnya pengetahuan pasien tentang pelayanan di FKTP, pasien } \\
\text { datang berobat hanya jika sakit saja }\end{array}$ & $13(19.1 \%)$ \\
\hline 5 & Pasien tidak membawa kartu BPJS pada saat kunjungan sehat & $13(19.1 \%)$ \\
\hline 6 & $\begin{array}{l}\text { Harus membuat fakta integritas dokter setiap bulan dan dikirim ke } \\
\text { BPJS setiap awal bulan }\end{array}$ & $12(17.6 \%)$ \\
\hline 7 & Pasien pindah tempat tinggal atau pindah faskes & $8(11.8 \%)$ \\
\hline 8 & Penginputan data yang kurang optimal oleh petugas $p$-care & $7(10,3 \%)$ \\
\hline 9 & $\begin{array}{l}\text { Peserta BPJS mengungak pembayaran BPJS atau peserta BPJS } \\
\text { sudah tidak aktif lagi }\end{array}$ & $6(8.8 \%)$ \\
\hline 10 & Kesulitan dalam memasukan kode penyakit & $3(4.4 \%)$ \\
\hline
\end{tabular}

Berdasarkan tabel 5 kesulitan lainnya dalam memenuhi target indikator Angka Kontak BPJS hanya menghitung 1 kali kunjungan dalam setiap bulan 19(27,9\%), gangguan internet, aplikasi $\mathrm{p}$-care lemot menyulitkan dalam menginput data di $p$-care
15(22.1\%), terlalu ribet pengisian p-care yang harus mengukur lingkar perut dan IMT yang menyulitkan 13(19.1\%), kurangnya pengetahuan pasien tentang pelayanan di FKTP, pasien datang berobat hanya jika sakit saja 13(19.1\%), Ppsien tidak membawa 
kartu BPJS pada saat kunjungan sehat 13(19.1\%), Harus membuat fakta integritas dokter setiap bulan dan dikirim ke BPJS setiap awal bulan 12(17.6\%), pasien pindah tempat tinggal atau pindah faskes $8(11.8 \%)$, Penginputan data yang kurang optimal oleh petugas p-care $7(10,3 \%)$, peserta BPJS mengungak pembayaran BPJS atau peserta BPJS sudah tidak aktif lagi 6(8.8\%), dan kesulitan dalam memasukan kode penyakit $3(4.4 \%)$.

\section{B. Gambaran Rasio Rujukan Rawat Jalan nonspesialistik (RNS) kajian pelaksanaan KBK BPJS pada FKTP di kota Jambi tahun 2019}

Tabel 6. Gambaran kesulitan dalam memenuhi target RNS di FKTP kota Jambi

\begin{tabular}{llcc}
\hline \multirow{2}{*}{ No } & \multirow{2}{*}{ Kesulitan dalam memenuhi target RNS } & \multicolumn{2}{c}{ Kesulitan } \\
\cline { 3 - 4 } & & Ya (\%) & Tidak (\%) \\
\hline 1 & Terlalu tingginya target $(<5 \%)$ & $14(20.6 \%)$ & $54(79.4 \%)$ \\
2 & Meningkatnya permintaan rujukan & $48(70.6 \%)$ & $20(29.4 \%)$ \\
3 & Keterbatasan tenaga dokter dan paramedic & $5(7.4 \%)$ & $63(92.6 \%)$ \\
4 & Kurangnya ketersediaan obat & $7(10.3 \%)$ & $61(89.7 \%)$ \\
5 & Kurangnya ketersediaan sarana dan prasarana & $10(14.7 \%)$ & $58(85.3 \%)$ \\
6 & Tidak optimalnya petugas p-care & $10(14.7 \%)$ & $58(85.3 \%)$
\end{tabular}

Berdasarkan tabel 6 kesulitan dalam optimalnya petugas p-care $10(14.7 \%)$ yang memenuhi target RNS Meningkatnya tidak merasa kesulitan 58( 85.3\%), permintaan rujukan $48(70.6 \%)$ yang tidak merasa kesulitan 20(29.4\%), terlalu tingginya kurangnya ketersediaan obat $7(10.3 \%)$ yang tidak merasa kesulitan 61(89.7\%), target $<5 \% 14(20.6 \%)$ yang tidak merasa keterbatasan tenaga dokter dan paramedis kesulitan 54(79.4\%), kurangnya ketersediaan $5(7.4 \%)$ yang tidak merasa kesulitan sarana dan prasarana 10(14.7\%) \%) yang 63(92.6\%).

tidak merasa kesulitan 58(85.3\%), tidak

Tabel 7. Gambaran kesulitan lainnya dalam memenuhi target indikator Rasio Rujukan Rawat Jalan non spesialistik (RNS) $<5 \%$

\begin{tabular}{clc}
\hline No & \multicolumn{1}{c}{ Kesulitan Memenuhi Target RNS } & Frekuensi \\
\hline 1 & Banyaknya permintaan pasien untuk dirujuk ke Rumah sakit & $25(36.8 \%)$ \\
2 & Feedback dari rumah sakit yang kurang jelas dalam penulisan surat & $13(19.1 \%)$ \\
& rujuk balik atau pasien rujuk balik yang tidak dikembalikan ke FKTP & \\
3 & Fasilitas dan sarana prasarana di FKTP belum memadai & $5(7.4 \%)$ \\
4 & Diagnosis non spesialistik dinaikan menjadi spesialistik & $4(5.9 \%)$ \\
5 & Gangguan aplikasi p-care & $4(5.9 \%)$ \\
\hline
\end{tabular}


Berdasarkan tabel 7 kesulitan lainnya dalam memenuhi target indikator Rasio Rujukan Rawat Jalan non spesialistik (RNS) banyaknya permintaan pasien untuk dirujuk ke Rumah sakit 25(36.8\%), feedback dari rumah sakit yang kurang jelas dalam penulisan surat rujuk balik atau pasien rujuk balik yang tidak dikembalikan ke FKTP 13(19.1\%), fasilitas dan sarana prasarana di FKTP belum memadai 5(7.4\%), diagnosis non spesialistik dinaikan menjadi spesialistik $4(5.9 \%)$ dan Gangguan aplikasi p-care $4(5.9 \%)$.

\section{Gambaran Rasio Peserta Prolanis Rutin Berkunjung (RPPB) kajian pelaksanaan KBK BPJS pada FKTP di kota Jambi tahun 2019}

Tabel 8. Gambaran terjadi kontak pada kegiatan prolanis di FKTP kota jambi

\begin{tabular}{llcc}
\hline \multirow{2}{*}{ No } & \multicolumn{2}{c}{ Kegiatan prolanis } & \multicolumn{2}{c}{ Terjadi kontak } \\
\cline { 3 - 4 } & & $68(100 \%)$ & Tidak (\%) \\
\hline 1 & Edukasi klub & $68(100 \%)$ & 0 \\
2 & Konsultasi medis & $68(100 \%)$ & 0 \\
3 & Pemeriksaan penunjang & $54(79.4 \%)$ & $14(20.6 \%)$ \\
4 & Home visit & $68(100 \%)$ & 0 \\
5 & Pelayanan obat rutin (PRB) & $54(79.4 \%)$ & $14(20.6 \%)$ \\
6 & Senam prolanis & & \\
\hline
\end{tabular}

Berdasarkan tabel 8 gambaran terjadi kontak pada kegiatan prolanis edukasi klub $68(100 \%)$ tidak terjadi kontak 0 , terjadi kontak konsultasi medis $68(100 \%)$ tidak terjadi kontak 0 , terjadi kontak pemeriksaan penunjang $68(100 \%)$ tidak terjadi kontak 0 , terjadi kontak PRB 68(100\%) tidak terjadi kontak 0, terjadi kontak home visit 54(79.4\%) tidak terjadi kontak $14(20,6 \%)$, terjadi kontak senam prolanis $54(79,4 \%)$ tidak terjadi kontak $14(20,6 \%)$.

Tabel 9. Gambaran kesulitan dalam memenuhi target Rasio peserta Prolanis Rutin Berkunjung (RPPB) di FKTP kota Jambi

\begin{tabular}{llcc}
\hline \multirow{2}{*}{ No } & \multicolumn{2}{c}{ Kesulitan dalam memenuhi target RPPB } & \multicolumn{2}{c}{ Kesulitan } \\
\cline { 3 - 4 } & & $35(51.5 \%)$ & $33(48.5 \%)$ \\
\hline 1 & Terlalu tinggi target yang ditetapkan ( $\geq 50 \%)$ & $7(10.3 \%)$ & $61(89.7 \%)$ \\
2 & Keterbatasan tenaga dokter dan paramedic & $27(39.7 \%)$ & $41(60.3 \%)$ \\
3 & Kurangnya dana operasional kegiatan prolanis & $13(19.1 \%)$ & $55(80.9 \%)$ \\
4 & Kurang optimalnya petugas P-care & $37(54.4 \%)$ & $31(45.6 \%)$ \\
5 & Jadwal senam yang tidak sesuai dengan peserta prolanis & & \\
\hline
\end{tabular}

Berdasarkan tabel 9 gambaran kesulitan dalam memenuhi target RPPB Jadwal senam yang tidak sesuai dengan peserta prolanis $37(54.4 \%)$ tidak merasa kesulitan 31(45.6\%), terlalu tinggi target yang ditetapkan $35(51.5 \%)$ tidak merasa kesulitan 
$33(48.5 \%)$, kurangnya dana operasional kegiatan prolanis $27(39.7 \%)$ tidak merasa kesulitan 41(60.3\%), kurang optimalnya petugas P-care 13(19.1\%) tidak merasa kesulitan 55(80.9\%), keterbatasan tenaga dokter dan paramedis $7(10.3 \%)$ tidak merasa kesulitan 61(89.7\%).

\section{Kesulitan lainnya dalam memenuhi target indikator Rasio Peserta Prolanis Rutin Berkunjung (RPPB) ( $\geq 50 \%)$}

\begin{tabular}{clc}
\hline No & \multicolumn{1}{c}{ Jenis Kesulitan Lainnya } & Frekuensi \\
\hline 1 & Peserta prolanis jarang ikut senam karena ada pekerjaan,sakit, tidak ada kendaraan dll & $34(50.0 \%)$ \\
2 & $\begin{array}{l}\text { Dana prolanis yang masuk ke BLUD dan tidak ada kewenangan FKTP mencairkan dana } \\
\text { tersebut jadi menggunakan dan FKTP itu sendiri }\end{array}$ & $20(29.4 \%)$ \\
3 & Peserta prolanis yang masih sedikit & $9(13.2 \%)$ \\
4 & Kurang optimal petugas prolanis & $5(7.4 \%)$ \\
5 & Tidak terflaggingnya peserta PRB ke p-care, padahal rutin ambil obat & $4(5.9 \%)$ \\
6 & Pasien datang hanya untuk mengambil obat PRB saja & $4(5.9 \%)$ \\
7 & Senam prolanis yang masih belum aktif & $4(5.9 \%)$ \\
\hline
\end{tabular}

Berdasarkan tabel 10 kesulitan lainnya dalam memenuhi target indikator Rasio Peserta Prolanis Rutin Berkunjung (RPPB) peserta prolanis jarang ikut senam karena ada pekerjaan, sakit, tidak ada kendaraan dII 34(50.0\%), dana prolanis yang masuk ke BLUD dan tidak ada kewenangan FKTP mencairkan dana tersebut jadi menggunakan dan FKTP itu sendiri

\section{KESIMPULAN}

Berdasarkan hasil penelitian dan pembahasan yang telah dilakukan tentang kajian pelaksanaan Kapitasi Berbasis Pemenuhan Komitmen Pelayanan (KBK) Badan Penyelenggara Jaminan Sosial Kesehatan (BPJS) pada Fasilitas Kesehatan Tingkat Pertama (FKTP) Kota Jambi tahun 2019 adalah sebagai berikut:

1. Faktor penyebab belum tercapainya target pemenuhan indikator Angka Kontak yang paling dominan disebabkan oleh terlalu tingginya
20(29.4\%), peserta prolanis yang masih sedikit $9(13.2 \%)$, kurang optimal petugas prolanis $5(7.4 \%)$, tidak terflaggingnya peserta PRB ke p-care, padahal rutin ambil obat $4(5.9 \%)$, pasien datang hanya untuk mengambil obat PRB saja $4(5.9 \%)$ dan $4(5.9 \%)$ senam prolanis yang masih belum aktif.

target yang harus dicapai $\geq 150$ permil, pasien berpindah tempat tinggal atau faskes, tidak optimalnya pertugas $\mathrm{p}$-care dan BPJS hanya menghitung 1 kali kunjungan dalam setiap bulan.

2. Faktor penyebab belum tercapainya target pemenuhan indikator Rasio Rujukan Rawat Jalan Nonspesialistik (RRNS) yang paling dominan disebabakan oleh meningkatnya permintaan rujukan, terlalu sedikitnya pasien yang 
diperbolehkan untuk dirujuk $<5 \%$ dan

kurangnya ketersediaan sarana dan prasarana.

3. Faktor penyebab belum tercapainya target pemenuhan indikator Rasio Peserta Prolanis Rutin Berkunjung
(RPPB) yang paling dominan disebabkan oleh jadwal prolanis yang tidak sesuai dengan peserta prolanis, tingginya target yang ditetapkan $\geq 50 \%$ dan kurangnya dana operasional kegiatan prolanis

\section{DAFTAR PUSTAKA}

1. Kemenkes RI. Summary for Policymakers. Buku Pegangan Jaminan Kesehatan Nasional.2013; : 1-30.

2. Noerdjoedianto, D. (2017). Kajian Ability To Pay (Atp) Bagi Calon Peserta Bpjs Kesehatan Dalam Pemilihan Besaran Iuran Di Propinsi Jambi Tahun 2015. Jambi Medical Journal "Jurnal Kedokteran Dan Kesehatan\&quot; 4(2).

3. Silvia Putri B. Pengaruh Kualitas Pelayanan Bpjs Kesehatan Terhadap Kepuasan Pengguna Perspektif Dokter Rumah Sakit Hermina Bogor. 2017; 2: 1-12.

4. BPJS Kesehatan. Pelayanan Kesehatan. Pandu Praktik pelayanan Kesehatan 2013; V: 1-78.

5. Moon S, Røttingen J-A, Frenk J. Global public goods for health: weaknesses and opportunities in the global health system. Health Economics, Policy and Law. Cambridge University Press; 2017;12(2):195-205.

6. BPJS Kesehatan. Monitoring dan Evaluasi Implementasi Kapitasi Berbasis Pemenuhan Komitmen Pelayanan (KBK). 2018. www.BPJS-Kesehatan.go.id.

7. Dr. Rusady, Maya A., M.Kes A. Peranan BPJS Kesehatan Dalam Peningkatan Pelayanan Kesehatan. Peran BPJS Kesehatan Dalam Peningkatan Pelayanan Kesehatan 2017; : 1-43.

8. kamariyah, kamariyah, arif, yulastri, \& dorisnita, dorisnita. (2017). Pengalaman Tenaga Kesehatan Tentang Pelayanan Bpjs Kesehatan Pada Fasilitas Pelayanan Kesehatan Primer Di Kota Jambi Tahun 2014. Jambi Medical Journal "Jurnal Kedokteran Dan Kesehatan\&quot; 4(2).

9. Peraturan Kemenkes RI dan BPJS Kesehatan nomor 2. Badan Penyelenggara Jaminan Sosial Kesehatan Nomor Hk.01.08/lii/980/2017 Tahun 2017 Nomor 2 Tahun 2017 Tentang Petunjuk Teknis Pelaksanaan Pembayaran Kapitasi Berbasis Pemenuhan Komitmen Pelayanan Pada Fasilitas Kesehatan Tingkat Pertama. 2017.

10. BPJS Kesehatan. Monitoring dan Evaluasi Implementasi Kapitasi Berbasis Pemenuhan Komitmen Pelayanan (KBK). 2019. www.BPJS-Kesehatan.go.id 